\title{
Evidence for TTAGG telomere repeats and rRNA gene clusters in leafhoppers of the genus Alebra (Hemiptera: Auchenorrhyncha: Cicadellidae)
}

\author{
VALENTINA G. KUZNETSOVA ${ }^{1}$, ANNA MARYAŃSKA-NADACHOWSKA², BORIS ANOKHIN ${ }^{1}$ \\ and Dora AGUIN-POMBO 3,4
}

\begin{abstract}
${ }^{1}$ Department of Karyosystematics, Zoological Institute, Saint-Petersburg, 199034, Russia; e-mail: valentina_kuznetsova@yahoo.com
${ }^{2}$ Institute of Systematics and Evolution of Animals, Polish Academy of Sciences, Kraków 31-016, Poland; e-mail: maryanska@isez.pan.krakow.pl

${ }^{3}$ University of Madeira, 9000-390 Funchal, Madeira, Portugal; e-mail: aguin@uma.pt

${ }^{4}$ Centro de Investigacao en Biodiversidade e Recursos Genéticos (CIBIO), Vairão, Portugal
\end{abstract}

Key words. Hemiptera, Cicadellidae, Alebra, karyotype, holokinetic chromosomes, C-heterochromatin, CMA 3 /DAPI, Ag-NOR, FISH, 18S rDNA, (TTAGG)

\begin{abstract}
The leafhopper genus Alebra Fieber, 1872 comprises a complex of morphologically similar species. The chromosome complements (karyotypes) of five Alebra species, i.e. A. albostriella, A. coryli, A. viridis, A. wahlbergi and a new, yet undescribed species, provisionally named Taxon 1 , were here investigated, three of these species (A. coryli, A. viridis, and Taxon 1) for the first time. The techniques applied included standard chromosome staining, fluorescence in situ hybridization (FISH) for mapping of $18 \mathrm{~S}$ rDNA and telomeric repeats (in every species), C-banding, AgNOR-banding and CMA,/DAPI- staining (in A. viridis). The species have a holokinetic type of chromosomes, as in other hemipterans. Karyotypes of all species are remarkably conserved with $2 \mathrm{n}=22+$ $\mathrm{X}(0) / \mathrm{XX}$ (male/female), one large and 10 medium pairs of autosomes and the X chromosome similar in size to larger chromosomes within this group. In every species, FISH identified the "classical" insect telomere repeat of TTAGG and rRNA gene clusters located on the homologues of a medium-sized pair of autosomes, presumably number 5 . Thus, speciation in Alebra has apparently not involved significant karyotypic changes. In $A$. viridis, rDNA sites were both Ag- and $\mathrm{CMA}_{3}$-positive and were located at an interstitial position. $\mathrm{C}$-banding revealed heterochromatic bands in the $\mathrm{X}$ chromosome and also in all but four pairs of autosomes, the bands were located at one telomere of a chromosome. C-bands were positive for $\mathrm{CMA}_{3}$ and negative for DAPI, suggesting that C-heterochromatin is mainly enriched in GC-pairs.
\end{abstract}

\section{INTRODUCTION}

Most previous cytogenetic studies on the suborder Auchenorrhyncha (Insecta: Hemiptera) were performed using conventional (routine) chromosome staining techniques. This approach allows the detection of gross karyotypic alterations, such as changes in chromosome number and size, and provides an overview of chromosome behaviour during mitosis and meiosis. So far, descriptions regarding specific chromosome regions, like C-heterochromatin and NORs, are scarce (reviewed in Kuznetsova \& Aguin-Pombo, in press). Over the last few years, the use of fluorescence in situ hybridization (FISH) has opened up a new area of research in different groups of insects with holokinetic chromosomes, making possible cytological identification as well as the molecular mapping of individual chromosomes within karyotypes (e.g. Manicardi et al., 2002; Yoshido et al., 2005; Monti et al., 2011; Grozeva et al., 2011, 2014). In the Auchenorrhyncha, this technique has so far only been applied to nine cicadomorphan species, including Mapuchea chilensis (Nielson, 1996) (Myerslopiidae) and eight species of the spittlebug genus Philaenus Stal, 1864 (Aphrophoridae) in which the distribution of $18 \mathrm{~S}$ rDNA sites and presence of the (TTAGG) ${ }_{n}$ telomeric motif were detected (Maryańska-Nadachowska et al., 2013; Golub et al., 2014; Kuznetsova et al., 2014).
The genus Alebra Fieber, 1872 is classified within the subfamily Typhlocybinae Kirschbaum 1868, one of the largest and most diversified of the auchenorrhynchan family Cicadellidae (leafhoppers). The latter includes nearly 22,000 (McKamey, 2002) or even 25,000 (Dietrich \& Rakitov, 2002) described species. To date, karyotypes in terms of chromosome numbers and sex chromosome systems are known for 289 species in 165 genera of Cicadellidae, among which 34 species (of the 5000 described) and 15 genera (of the 450 accepted) belong to the subfamily Typhlocybinae (de Lello et al., 1982; Aguin-Pombo et al., 2006, 2007; de Bigliardo et al., 2011; Juan, 2011; Kuznetsova et al., 2013; for other references and discussion, see reviews of Kirillova, 1988; Emeljanov \& Kirillova, 1990; Kuznetsova \& Aguin-Pombo, in press). Until now, neither the karyotypes of Typhlocybinae nor indeed Cicadellidae as a whole have ever been subjected to differential chromosome staining of any description.

The taxonomy of the genus Alebra is difficult because most species do not show any apparent differences in male genital structures. Based on slight but consistent morphological differences three different groups within the genus are recognized occurring in North America (Hamilton, 1995), Europe (Drosopoulos \& Loukas, 1988; Gillham, 1991; Aguin-Pombo, 2002) and Asia (Wagner, 1940; 
Dworakowska, 1968, 1971). The European group is represented by five morphologically similar, but biologically distinct species: A. albostriella (Fallen, 1826), A. sorbi Wagner, 1940, A. wahlbergi (Boheman, 1845), A. coryli Le Quesne, 1977, A. viridis Rey (Gillham, 1991) and several cryptic yet unnamed taxa (Aguin-Pombo, 2002). Nymphs and adults of these species are mesophyll-feeders being associated with a large number of broad-leaved trees and shrubs. Although these leafhoppers are usually found in small numbers, some species can occasionally become pests on chestnuts, hazel and other plants (Viggiani, 1971; Lauterer, 1986; Drosopoulos et al., 1987).

Cytologically, the genus Alebra is poorly explored. To date, only two species, A. albostriella and A. wahlbergi, have been studied, both of which possess the karyotype $2 \mathrm{n}$ $=22+\mathrm{X}(0) / \mathrm{XX}$ (male/female). In a total of 13 analyzed populations of these species from Greece, a lot of meiotic abnormalities and polymorphism for B-chromosomes were detected (Kuznetsova et al., 2013).

In order to continue cytological investigation of the genus, we have in the present study investigated karyotypes of three further species, $A$. coryli, $A$. viridis and one presumably new yet undescribed species named here as Taxon 1. In addition, we reinvestigated karyotypes of $A$. albostriella (in two earlier unexplored populations) and $A$. wahlbergi (for the first time in females). Here we show the results of FISH experiments to investigate the distribution of 18S rRNA gene clusters and the presence/absence of the (TTAGG) ${ }_{n}$ telomeric motif in all the aforementioned species. This is only the third physical mapping effort reported for the auchenorrhynchan genomes using FISH. In addition, in $A$. viridis, a more detailed cytogenetic analysis was performed using $\mathrm{C}$-banding, silver staining and fluorochrome DAPI/CMA 3 -staining.

\section{MATERIAL AND METHODS}

\section{Source of material}

The four species of the "albostriella" group presented in the western Palaearctic were included in this study, namely: A. albostriella, A. wahlbergi, A. coryli, and A. viridis. In addition, specimens assigned to a presumably new, yet hitherto undescribed species, provisionally named here as Taxon 1 , were studied. This last species was distinguished according to its food plant associations, distribution, colouration, shape of male abdominal apodemes and genetic differences (Aguin-Pombo, 2002). Leafhoppers were sampled with a sweep net from different food plants foliage in several localities of Greece and Portugal. For each species, collection sites, food plants, number of specimens examined and the chromosome staining techniques applied are presented in Table 1.

\section{Chromosome preparations}

Adult males and females were fixed immediately after collection in the field in Carnoy fixative (96\% ethanol and glacial acetic acid, $3: 1)$ and kept at $5^{\circ} \mathrm{C}$ and in part at room temperature until slides were made. The storage temperature was found to have no effect on the quality of chromosome preparations. In males, preparations were made from testes, which were dissected in a drop of $45 \%$ acetic acid and squashed under a coverslip on a glass microscope slide. In females, preparations were made from ovaries and from mature eggs. The slides were frozen using dry ice, the coverslips were removed with a razor blade, and the preparations then dehydrated in fresh fixative $(3: 1)$ for 20 min and air dried. Slides were first examined under a phase-contrast microscope to check for the availability of meiotic divisions and the quality of chromosome spreads.

\section{Standard chromosome staining}

The preparations were stained with $2 \%$ aceto-orcein or/and using the Schiff-Giemsa method developed by Grozeva \& Nokkala (1996) for the true bugs and previously applied successfully to many auchenorrhynchan species (e.g. Kuznetsova et al., 2009). In brief, the preparations were subjected to hydrolysis in $1 \mathrm{M} \mathrm{HCl}$ first at room temperature for $20 \mathrm{~min}$ and then at $60^{\circ} \mathrm{C}$ for $8 \mathrm{~min}$, and thereafter stained in Schiff's reagent for $20 \mathrm{~min}$. After rinsing thoroughly in distilled water, the slides were additionally stained with 4\% Giemsa in Sorensen's phosphate buffer, $\mathrm{pH}$ 6.8, for 20 $\mathrm{min}$. The slides were rinsed briefly in distilled water, air-dried and mounted in Entellan mounting medium (Merk, NJ, USA).

\section{Conventional chromosome bandings}

Banding techniques were used to investigate the karyotype of one of the studied species, A. viridis. The techniques applied included: silver-staining for the visualization of nucleolus organizing regions (NORs); C-banding for the detection of constitutive heterochromatic regions (C-heterochromatin); GC-specific $\mathrm{CMA}_{3}$ staining and AT-specific DAPI staining to reveal the molecular composition of C-heterochromatic bands.

Ag-banding was performed using the technique described in Howell \& Black (1980). Slides were treated with a mixture of gelatin solution $/ \mathrm{AgNO}_{3}$ solution $(50 \%)$ at $65^{\circ} \mathrm{C}$ for $6-8 \mathrm{~min}$ in a moist chamber, rinsed three times with distilled water, air dried and stained with $4 \%$ Giemsa.

C-banding was performed according to Sumner (1972). Slides were treated at $30^{\circ} \mathrm{C}$ with a saturated solution of $\mathrm{Ba}(\mathrm{OH})_{2}$, for periods ranging from 10 to $30 \mathrm{~min}$. After being washed in distilled water, slides were incubated in $2 \times \mathrm{SSC}$ at $60^{\circ} \mathrm{C}$ for $60 \mathrm{~min}$, and then stained in a $5 \%$ Giemsa solution.

Treatment using DAPI (4'-6'-diamidino-2-phenylindole) and $\mathrm{CMA}_{3}$ (chromomycin $\mathrm{A}_{3}$ ) was done according to Schweizer (1976) and Donlon \& Magenis (1983), respectively, with minor modifications. First, C-banding pretreatment was performed using $0.2 \mathrm{M} \mathrm{HCl}$ at room temperature for $30 \mathrm{~min}$, followed by 7-8 min treatment in saturated $\mathrm{Ba}(\mathrm{OH})_{2}$ at room temperature and then an incubation in $2 \times \mathrm{SSC}$ at $60^{\circ} \mathrm{C}$ for $1 \mathrm{~h}$. Thereafter, the preparations (omitting Giemsa treatment) were stained first with $\mathrm{CMA}_{3}$ $(0.4 \mu \mathrm{g} / \mathrm{ml})$ for $25 \mathrm{~min}$ and then with DAPI $(0.4 \mu \mathrm{g} / \mathrm{ml})$ for $5 \mathrm{~min}$. After staining, the preparations were rinsed in McIlvaine buffer, $\mathrm{pH} 7$, and mounted in an antifade medium $(700 \mu \mathrm{l}$ of glycerol, $300 \mu \mathrm{l}$ of $10 \mathrm{mM}$ McIlvaine buffer, $\mathrm{pH}$ 7, and $10 \mathrm{mg}$ of N-propyl gallate).

\section{Fluorescence in situ hybridization (FISH)}

To study the karyotypes of $A$. albostriella (from Castanea sati$v a$ and Alnus sp.), A. wahlbergi, A. viridis, A. coryli, and Taxon 1, FISH with $18 \mathrm{~S}$ rDNA and (TTAGG) ${ }_{n}$ telomeric probes was used.

DNA isolation, PCR amplification, probe generation

Genomic DNA from a male Pyrhocoris apterus (L., 1758) (Heteroptera: Pyrrhocoridae) was isolated using a Chelex-100 extraction method. FISH with $18 \mathrm{~S}$ rRNA gene and telomeric (TTAGG) ${ }_{n}$ probes was performed on chromosomes of all of five Alebra species examined. The $18 \mathrm{~S}$ rRNA probe was PCR amplified (see Grozeva et al., 2014, for details of the primers and PCR conditions used) from the genomic DNA of P. apterus, and labelled by PCR with biotin. The telomere probe was PCR amplified and labelled with Rhodamine-5-dUTP (GeneCraft, Köln, Germany) (see Grozeva et al., 2014). 
TABLE 1. Leafhoppers studied and cytogenetic techniques used.

\begin{tabular}{|c|c|c|c|c|c|c|}
\hline Species & Sampling locality & $\begin{array}{l}\text { Sampling } \\
\text { date }\end{array}$ & $\begin{array}{l}\text { Food } \\
\text { plant }\end{array}$ & $\begin{array}{l}\text { No. } \delta / Q+ \\
\text { studied }\end{array}$ & Technique & Figures \\
\hline \multirow{2}{*}{$\begin{array}{l}\text { A. albostriella } \\
\text { (Fallen, 1826) }\end{array}$} & $\begin{array}{l}\text { Portugal, Portoalegre } \\
\text { (Ammaia) } 525 \mathrm{~m} \text { a.s.l. }\end{array}$ & 27.vii.2008 & Alnus sp. & $4 / 0$ & $\begin{array}{l}\text { Standard chromosome } \\
\text { staining and FISH }\end{array}$ & $2 \mathrm{c}$ \\
\hline & $\begin{array}{c}\text { Portugal, Chaves } \\
\text { (Langarelhos) } 800 \mathrm{~m} \text { a.s.1. }\end{array}$ & 27.vii.2008 & $\begin{array}{l}\text { Castanea } \\
\text { sativa }\end{array}$ & $3 / 0$ & $\begin{array}{l}\text { Standard chromosome } \\
\text { staining and FISH }\end{array}$ & $2 \mathrm{~d}$ \\
\hline \multirow{2}{*}{$\begin{array}{l}\text { A. wahlbergi } \\
\text { (Boheman, 1845) }\end{array}$} & $\begin{array}{c}\text { Greece, Peloponnese } \\
\text { (Kastanitsa) } 900 \text { m a.s.l. }\end{array}$ & 10.vii.1989 & $\begin{array}{l}\text { Castanea } \\
\text { sativa }\end{array}$ & $0 / 1$ & $\begin{array}{l}\text { Standard chromosome } \\
\text { staining }\end{array}$ & 11 \\
\hline & $\begin{array}{l}\text { Greece, Florina (Caries) } \\
1100 \text { m a.s.l. }\end{array}$ & 27.vii.2009 & $\begin{array}{c}\text { Acer } \\
\text { opalus }\end{array}$ & $3 / 0$ & FISH & $2 \mathrm{f}$ \\
\hline \multirow{2}{*}{$\begin{array}{l}\text { A. coryli } \\
\text { Le Quesne, } 1977\end{array}$} & $\begin{array}{c}\text { Greece, Karpenisi } \\
\text { (Agios Nicolaos) } 980 \mathrm{~m} \text { a.s.l. }\end{array}$ & 8.vii.1991 & $\begin{array}{l}\text { Quercus } \\
\text { frainetto }\end{array}$ & $1 / 0$ & $\begin{array}{c}\text { Standard chromosome } \\
\text { staining }\end{array}$ & $1 \mathrm{j}, \mathrm{k}$ \\
\hline & $\begin{array}{c}\text { Greece, Florina } \\
\text { (Agia Triada) } 1200 \mathrm{~m} \text { a.s.l. }\end{array}$ & 28.vii.2009 & $\begin{array}{l}\text { Corylus } \\
\text { avellana }\end{array}$ & $1 / 0$ & FISH & $2 \mathrm{e}$ \\
\hline \multirow{3}{*}{$\begin{array}{l}\text { A. viridis } \\
\text { Rey, } 1894\end{array}$} & $\begin{array}{c}\text { Greece, Karpenisi } \\
\text { (Agios Nicolaos) } 1050 \text { m a.s.l. }\end{array}$ & 1.viii.1991 & $\begin{array}{l}\text { Castanea } \\
\text { sativa }\end{array}$ & $1 / 0$ & $\begin{array}{c}\text { Standard chromosome } \\
\text { staining }\end{array}$ & $1 \mathrm{c}$ \\
\hline & $\begin{array}{c}\text { Portugal, Madeira Il. (Curral das } \\
\text { Freiras-Eira do Serrado) } 1000 \mathrm{~m} \text { a.s.l. }\end{array}$ & $\begin{array}{c}15 .-30 . \\
\text { vii. } 2010\end{array}$ & $\begin{array}{l}\text { Castanea } \\
\text { sativa }\end{array}$ & $14 / 1$ & $\begin{array}{l}\text { Standard chromosome } \\
\text { staining }\end{array}$ & $1 \mathrm{a}, \mathrm{b}$ \\
\hline & $\begin{array}{c}\text { Spain, Salamanca } \\
\text { (La Alberca) } 1050 \mathrm{~m} \text { a.s.l. }\end{array}$ & 24.vii.2008 & $\begin{array}{l}\text { Castanea } \\
\text { sativa }\end{array}$ & $7 / 0$ & $\begin{array}{l}\text { AgNOR-, C-, DAPI/CMA } \\
\text { bandings and FISH }\end{array}$ & $\begin{array}{l}1 \mathrm{~d}-\mathrm{i} \\
2 \mathrm{a}, \mathrm{b}\end{array}$ \\
\hline Taxon 1 & $\begin{array}{l}\text { Portugal, Beira Interior } \\
\text { (Guarda) } 875 \mathrm{~m} \text { a.s.l. }\end{array}$ & 23.vii.2008 & Quercus sp. & $4 / 0$ & $\begin{array}{l}\text { Standard chromosome } \\
\text { staining and FISH }\end{array}$ & $1 \mathrm{~m}, 2 \mathrm{~g}$ \\
\hline
\end{tabular}

\section{FISH procedure}

This was performed as described by Schwarzacher \& HeslopHarrison (2000) with modifications (Grozeva et al., 2014). Chromosome preparations were dehydrated through $70 / 80 / 96 \%$ ethanol at RT (room temperature) and treated with $100 \mu \mathrm{g} / \mathrm{ml} \mathrm{RNaseA}$ (Sigma-Aldrich, St. Louis, MO, USA) for $60 \mathrm{~min}$ at $37^{\circ} \mathrm{C}$ in a humid chamber; washed three times in $2 \times \operatorname{SSC}(5$ min each) at RT; dehydrated through $70 / 80 / 96 \%$ ethanol at RT; incubated in $5 \mathrm{mg} / \mathrm{ml}$ pepsin in $0.01 \mathrm{M} \mathrm{HCl}$ for $15 \mathrm{~min}$ at $37^{\circ} \mathrm{C}$; washed sequentially in $1 \times \mathrm{PBS}$, in $1 \times \mathrm{PBS} / 0.05 \mathrm{M} \mathrm{MgCl}_{2}$ for 5 min each, in $1 \%$ PFA in $1 \times \mathrm{PBS} / 0.05 \mathrm{M} \mathrm{MgCl}_{2}$ for $10 \mathrm{~min}$, in $1 \times \mathrm{PBS}$ for 5 min, in $1 \times \mathrm{PBS} / 0.05 \mathrm{M} \mathrm{MgCl}_{2}$ for 5 min at RT each; dehydrated through $70 / 80 / 96 \%$ ethanol at RT or ice cold and finally, dried. After pretreatment, a hybridization mixture containing about 100 ng of labelled probe, $50 \%$ formamide, $2 \times \mathrm{SSC}, 10 \%(\mathrm{w} / \mathrm{v}) \mathrm{dex}-$ tran sulfate, $1 \%(\mathrm{w} / \mathrm{v})$ Tween 20 and $10 \mu \mathrm{g}$ salmon-sperm DNA was added on preparations. Slides were mounted using glass coverslips and rubber cement. The slides were denatured for $5 \mathrm{~min}$ at $75^{\circ} \mathrm{C}$, and then incubated for $42-44 \mathrm{~h}$ at $37^{\circ} \mathrm{C}$. Following hybridization, they were washed in $2 \times \mathrm{SSC}$ for $3 \mathrm{~min}$ at $45^{\circ} \mathrm{C}$, then in $50 \%$ formamide in $2 \times \mathrm{SSC}$ for $10 \mathrm{~min}$ at $45^{\circ} \mathrm{C}$, twice in $2 \times$ $\mathrm{SSC}\left(10 \mathrm{~min}\right.$ each) at $45^{\circ} \mathrm{C}$, and blocked in $1.5 \%(\mathrm{w} / \mathrm{v}) \mathrm{BSA} / 4 \times$ $\mathrm{SSC} / 0.1 \%$ Tween 20 for $30 \mathrm{~min}$ at $37^{\circ} \mathrm{C}$ in a humid chamber. The $18 \mathrm{~S}$ rRNA gene probe was detected with $5 \mu \mathrm{g} / \mathrm{ml}$ Avidin-Alexa Fluor 488 (Invitrogen, Carlsbad, CA, USA). Detection was performed in $1.5 \% \mathrm{BSA} / 4 \times \mathrm{SSC} / 0.1 \%$ Tween 20 for $1 \mathrm{~h}$ at $37^{\circ} \mathrm{C}$. Slides were washed three times in $4 \times \mathrm{SSC} / 0.02 \%$ Tween $20(10$ min each) at $45^{\circ} \mathrm{C}$ and dehydrated through $70 / 80 / 96 \%$ ethanol at RT. Chromosomes were mounted in an antifade medium (ProLong Gold antifade reagent with DAPI, Invitrogen) and covered with a glass coverslip.

\section{Microscopy and imaging}

Images were taken using a Leica DM 6000 B microscope with a $100 \times$ objective, Leica DFC 345 FX camera and Leica Application Suite 3.7 software with an Image Overlay module (Leica
Microsystems Wetzlar GmbH, Germany). The filter sets applied were A, L5, N21 (Leica Microsystems, Wetzlar, Germany).

\section{RESULTS}

\section{Testes and ovaries}

In each of the Alebra species examined, testes in adult males were located ventrally in the anterior end of the abdomen and composed of five small roundish and transparent testicular lobes (follicles) each. Ovaries in mature females contained six small roundish telotrophic ovarioles each.

\section{Chromosome complements}

Representative mitotic and/or meiotic images of $A$. viridis, A. wahlbergi, A. coryli and Taxon 1 subjected to the different techniques applied (except FISH) are shown in Fig. 1a-m. Mitotic and meiotic images of $A$. viridis and meiotic ones for A. coryli, A. wahlbergi, Taxon 1 and $A$. albostriella (from Castanea sativa and Alnus sp., respectively) subjected to FISH with the $18 \mathrm{~S}$ rDNA and TTAGG probes are shown in Fig. 2a-g. The karyotypes of $A$. coryli, $A$. viridis, Taxon I and A. albostriella collected from Alnus sp. were studied here for the first time. All the studied species were found to display the same chromosome complement, $2 n=22+X X$ in females and $2 n=22+X$ in males. The chromosomes possessed no primary constrictions, i.e. centromeres (see Figs 1a, b, d-f and 2a). In every species examined, the male karyotype consisted of one very large pair and ten medium pairs of autosomes, whilst the X chromosome was similar in size to the larger chromosomes within this group (see Fig. 1a, b, f). In male cells during the diakinesis and metaphase I (MI) stages of meiosis, 11 bivalents and a univalent $\mathrm{X}$ chromosome were present, $\mathrm{n}=$ $12(11 \mathrm{AA}+\mathrm{X})($ Figs 1c, g, h-j, m and 2b-g). Occasionally, 


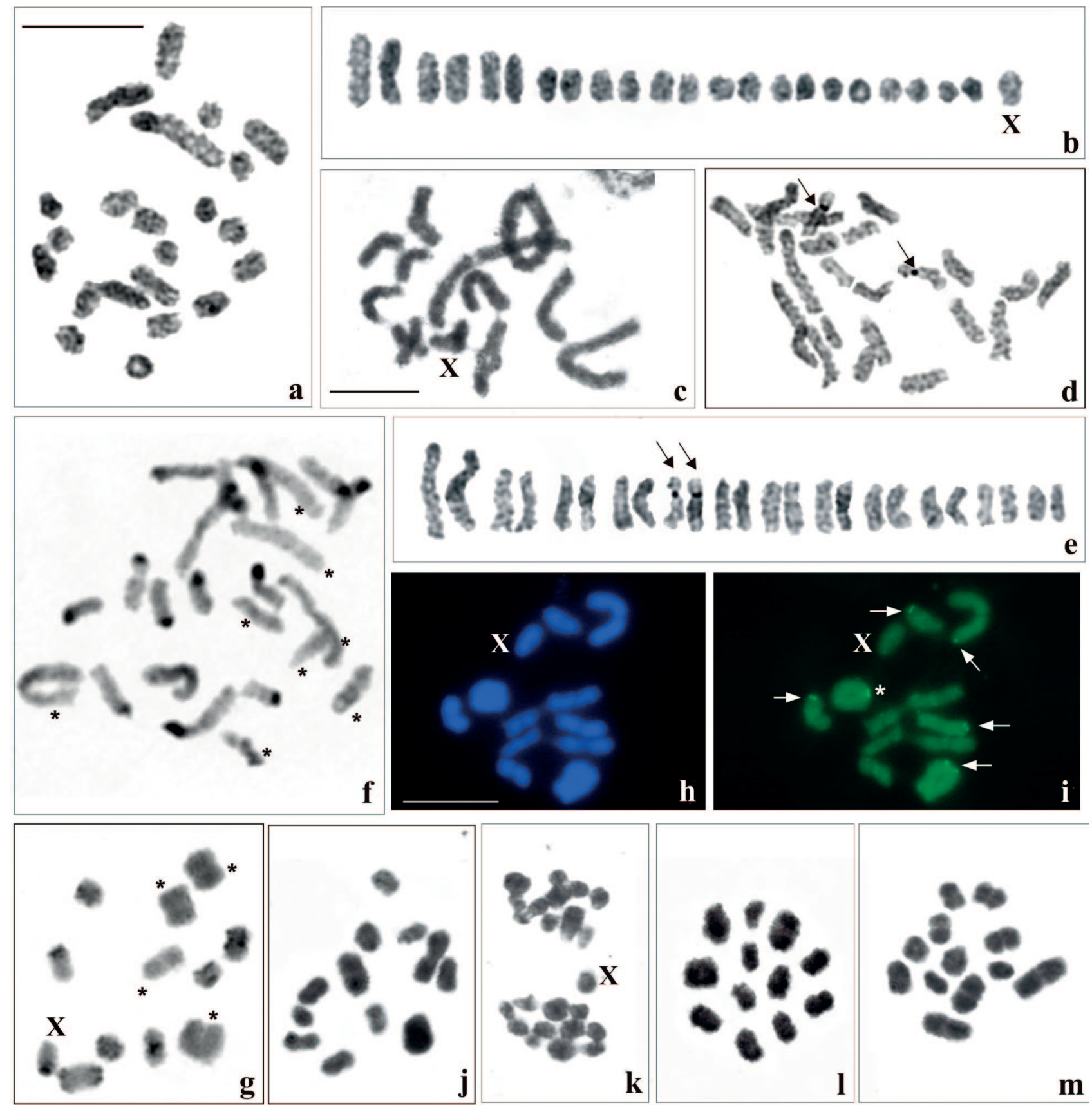

Fig. 1a-m. The karyotypes of Alebra spp: standard staining (a-c, j-m), silver staining (d, e), C-banding (f, g) and fluorochrome

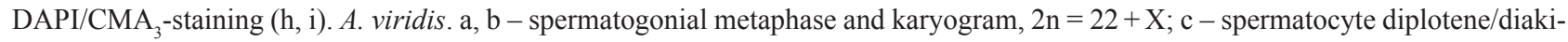
nesis, $\mathrm{n}=11 \mathrm{AA}+\mathrm{X}$, with bivalents displaying one to two chiasmata of terminal/subterminal or interstitial localizations; $\mathrm{d}, \mathrm{e}-\mathrm{oogonial}$ prometaphase and karyogram with NORs (arrows) located interstitially on a pair of medium-sized autosomes; f - spermatogonial prometaphase showing terminal C-bands at one end of all but 8 (asterisks) chromosomes; $\mathrm{g}$ - spermatocyte MI showing C-bands on all but 4 (asterisks) bivalents and on X chromosome; $\mathrm{h}, \mathrm{i}$ - one and the same diakinesis after DAPI-staining (h) and $\mathrm{CMA}_{3}$-staining (i). Signals are absent after DAPI and present after $\mathrm{CMA}_{3}$ in at least 5 bivalents (arrows) including NOR-bivalent (asterisk). A. coryli. $\mathrm{j}-\mathrm{MI}$ with $\mathrm{n}=11 \mathrm{AA}+\mathrm{X}(\mathrm{j}) ; \mathrm{k}-$ anaphase I with lagging $\mathrm{X}$ chromosome. A. wahlbergi. $1-$ oogonial MI with $\mathrm{n}=11 \mathrm{AA}+\mathrm{XX}$. Taxon I. $\mathrm{m}-$ MI with $\mathrm{n}=11 \mathrm{AA}+\mathrm{X}$. Bar $=10 \mu \mathrm{m}$.

the number of chromosomes in the prophase/metaphase nuclei was higher or lower, most likely relating to some kind of meiotic disturbance (e.g. Fig. 2f, g). The majority of bivalents displayed a single subterminal/terminal or rarely interstitial chiasma, but two chiasmata were a common finding in larger bivalents (e.g. Figs $1 \mathrm{c}$ and $2 \mathrm{c}-\mathrm{e}$ ). At anaphase I (AI), autosomal bivalents and X-chromosome divided reductionally, with $\mathrm{X}$ chromosome frequently lag- ging behind autosomes, and the two daughter MII cells showed hence 11 (only autosomes) and 12 (plus X) chromosomes, respectively (e.g. Fig. 1k). The stage between two meiotic divisions, interkinesis, was absent, and the second division occurred immediately after the first one. In females, oogonial prometaphases showed 24 chromosomes (e.g. Fig. 1d, e). Additionally, it was possible to count the number of bivalents at MI in a single egg of $A$. viridis and 

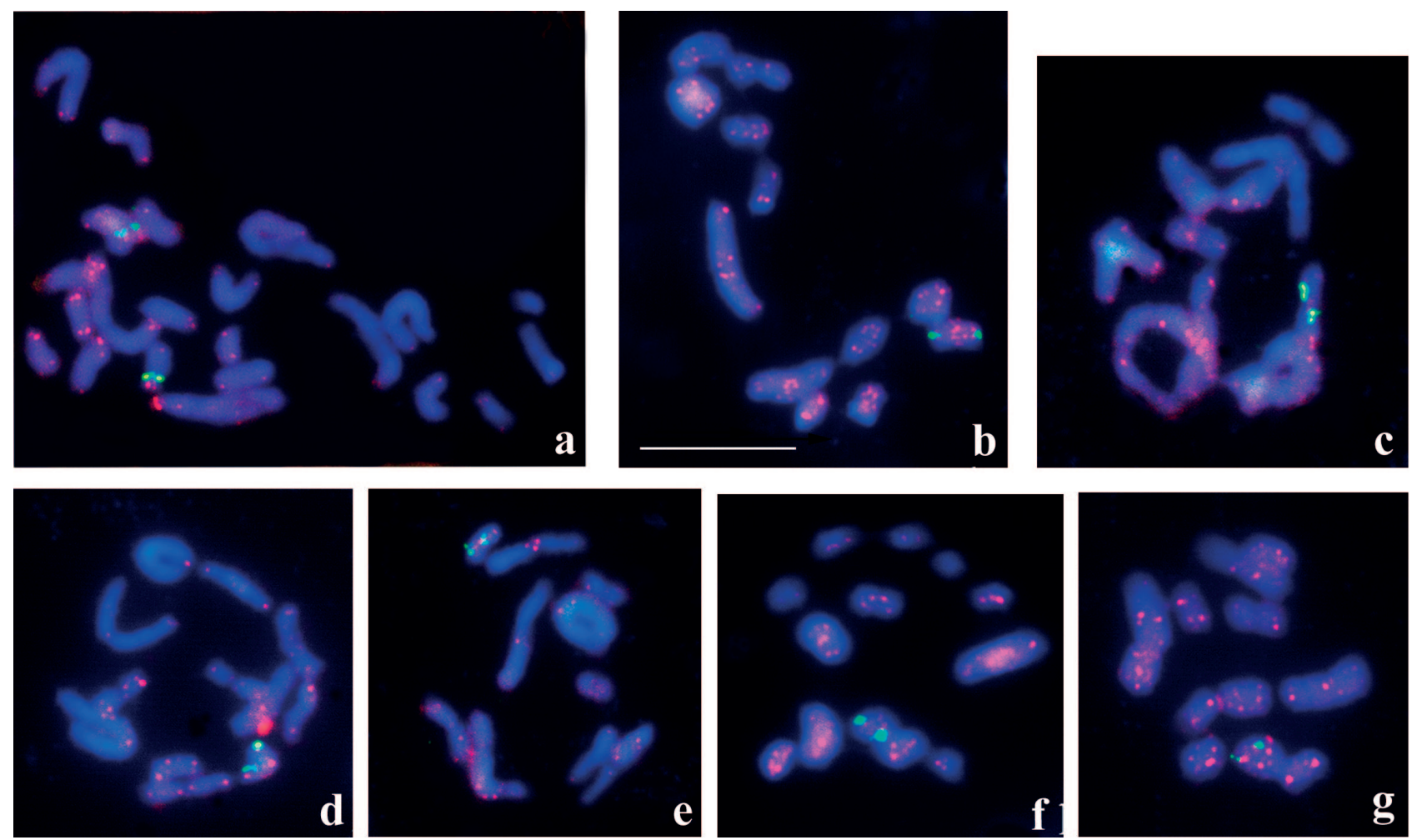

Fig. 2. Localization of rRNA gene clusters (green signals) and TTAGG telomeric repeats (red signals) on male mitotic (a) and meiotic (b-g) chromosomes of Alebra species. A. viridis - oogonial prometaphase (a) and diakinesis/MI (b); A. albostriella from Alnus sp. diakinesis (c) and from C. sativa - diakinesis (d); A. coryli - diakinesis (e); A. wahlbergi - MI with one additional element (f); Taxon 1 - diakinesis/MI (g). Bar $=10 \mu \mathrm{m}$.

A. albostriella (from Castanea sativa), respectively, and in two eggs of $A$. wahlbergi. In every case, 12 bivalents were present, however, the sex chromosome bivalent could not be identified among them (e.g. Fig. 11).

\section{AgNOR-, C- and DAPI/CMA_-banding}

These techniques were applied to $A$. viridis. In a silverstained oogonial prometaphase (Fig. 1d, e), argentumpositive sites, NORs, were present in a medium-sized pair of autosomes, presumably number 5 , located at a distance well away from the end of every homologue. After C-banding, spermatogonial prometaphases showed heterochromatic regions (as C-bands) in all but eight chromosomes (Fig. 1f) whilst MI in all but four bivalents and in the $\mathrm{X}$ (Fig. 1g). In every case, C-bands were localized at only one telomere of a chromosome. C-negative autosomes were the three largest ones and one medium-sized pair marked with asterisks in Figs $1 \mathrm{f}$ and 1g. As indicated in Figs $1 \mathrm{~h}$ and 1i, one and the same cell at diakinesis subjected to DAPI- and $\mathrm{CMA}_{3}$-staining, respectively, showed an absence of DAPIpositive signals (Fig. 1h) and presence of $\mathrm{CMA}_{3}$-positive signals on at least six bivalents (arrows), including that bearing the NOR (asterisk) (Fig. 1i).

\section{Fluorescence in situ hybridization (FISH)}

Chromosomal location of rDNA loci

In $A$. viridis, as expected from the results of both AgNOR- and $\mathrm{CMA}_{3}$-staining (Fig. 1d, e, i), the $18 \mathrm{~S}$ rDNA probe yielded specific hybridization signals at a subterminal region of every homologue of a medium-sized pair of autosomes (Fig. 2a, b; green spots). In other species examined, signals were likewise observed at subterminal regions of homologous chromosomes of a medium-sized bivalent (Fig. 2c-g; green spots). The occurrence of an rDNA-FISH signal at one end of each of the synapsed homologues of the NOR-bivalent allowed discrimination of the two chromosome ends of a homologue and hence allowed assessment of the kinetic behaviour of each chromosome end during the first meiotic division. At diakinesis/metaphase I, this bivalent could be seen oriented with homologous "kinetic" telomeres towards the opposite poles: the kinetic activity in both homologues could be present either at the chromosomal ends with signals (e.g. Fig. 2b, d) or at the ends without signals (e.g. Fig. c). As a whole, 29 cells were analyzed, and the frequencies of both orientations were similar (13 against 16).

\section{The molecular structure of telomeres}

In each of the Alebra species examined (Table 1), FISH using the TTAGG repeat as a probe showed the presence of hybridization signals at the ends of chromosomes (Fig. 2a-g; red spots). At diakinesis/MI, the bivalents most commonly revealed four signals, two in each of the homologous chromosomes of a bivalent (Fig. 2b-g).

\section{DISCUSSION}

As revealed in the present study, the leafhopper genus Alebra presents remarkable cytogenetic uniformity in the five species studied to date, despite the fact that some species were collected from different food plants (A. albostri- 
ella from Castanea sativa, Alnus sp., Fagus sylvatica and Quercus certis; A. wahlbergi from Acer opalus, Castanea sativa and Ulmus sp.; A. coryli from Quercus frainetto and Corylus avellana) and also from distant geographical localities, i.e. Greece, Portugal and Spain (Kuznetsova et al., 2013; present paper). Like other hemipterans, the species studied are characterized by holokinetic chromosomes, i.e., chromosomes with non-localized centromeres. Both male and female karyotypes were identical in terms of chromosome number and structure, i.e. $2 \mathrm{n}=22+\mathrm{XX} / \mathrm{X}(0)$, with one very large pair of autosomes, the remaining pairs gradually decrease in size, and with the $\mathrm{X}$ chromosome close in size to the medium-sized autosomes. Among Cicadellidae, both $\mathrm{X}(0)$ and $\mathrm{XY}$ sex chromosome systems occur, the latter only occasionally, whilst the presently known chromosome numbers vary from 7 to 27 in male diploid complements, the most frequent numbers lying between 11 and 23 (Kirillova, 1988; Wei, 2010; Juan, 2011; Kuznetsova \& Aguin-Pombo, in press). Thus, our results on the Alebra species here investigated fall within this range.

The uniformity in chromosome number in Alebra contrasts with the fairly variable number found in other genera of Typhlocybinae. This variability, although always within narrow limits, makes it difficult to establish the most characteristic number for each genus and for the subfamily as a whole. For example, the 19 species of the genus Eurhadina Haupt, 1929, which have been studied cytologically, vary broadly in chromosome number, with males showing karyotypes comprising $2 \mathrm{n}=11$ ( 1 species), 13 (6 species), 15 (1 species), 17 (7 species), and 19 (4 species) (Halkka, 1959; Juan, 2011). The genus Empoasca Walsh, 1864 is another group which seems to display a striking range in terms of chromosome number. This cosmopolitan genus with more than 1,000 described species is known to be diverse and by far the most species-rich genus within Cicadellidae (Southern \& Dietrich, 2010). Apart from several parthenogenetic forms, most likely triploid (Aguin-Pombo et al., 2006), the 13 diploid bisexual species of Empoasca examined so far have $2 \mathrm{n}=15$ ( 4 species), 17 ( 3 species), 19 (4 species), and 21 (2 species) (Kirillova, 1988; Aguin-Pombo et al., 2006; Juan, 2011). It is argued by Southern \& Dietrich (2010) that the genus requires comprehensive revision, and a cytogenetic approach might be important in the context of the systematics of this group. Theoretically, because of the holokinetic structure of the chromosomes, chromosome fusions and fissions can more easily operate in holokinetic groups, producing a variability of chromosome number (White, 1973). Simple fusion and fission of chromosomes are most probably associated with the divergence of the above mentioned genera. However, the genus Alebra with its conservative chromosome number, $2 n=23 / 24$ (male/ female) in the 5 studied species, seems to be an exception to this general rule, at least within Typhlocybinae.

The cytogenetic uniformity of this genus is further reinforced by the results of our FISH experiments, which detected 18S rRNA gene clusters, presumably, on the same pair of autosomes in every species examined. These findings contrast with those in the species of the genus Phi- laenus which differ from one another in the number and distribution of 18S rDNA (Maryańska-Nadachowska et al., 2013). In organisms with holokinetic chromosomes, rDNA sites tend to occupy terminal regions of chromosomes. For example, of the 92 species of heteropterans used for determining the number and location of rDNA sites, 86 species had these sites at a terminal position (reviewed in Grozeva et al., 2014). This suggests the existence of some limitations regarding the establishment of non-terminal rDNA sites in holokinetic chromosomes. Heckmann et al. (2011) hypothesized that the terminal location of rDNA might be a functional requirement to ensure chromosome stability in holokinetic karyotypes. According to their hypothesis, a secondary constriction (a site of NOR location) in the interstitial region would break the kinetochore plate along the holokinetic chromosome and result in a condition similar to an unstable dicentric chromosome, with consequent derangements in mitotic segregation. However, although there may be selection pressures which favor the terminal location of rDNA sites in holokinetic chromosomes (Roa \& Guerra, 2012), data of some groups indicate that there are no strict restrictions to the functioning of rDNA clusters in other positions (e.g. Fenton et al., 1994; Kuznetsova et al., 2009; Nguyen et al., 2010; Maryańska-Nadachowska et al., 2013; Grozeva et al., 2014). In Alebra species, simultaneous labelling with telomeric and 18S rDNA probes (these results) showed that ribosomal genes were not located in the functional region of the telomere. Moreover, based on observation of meiotic stages, the FISH-rDNA sites could be referred to as terminal, however in silver-stained mitotic chromosomes of $A$. viridis active NORs were found positioned at a distance well away from the end of every homologue thereby suggesting that they were in fact of an interstitial location.

The molecular structure of telomeres in insects has, over the past decade or so, received special attention (e.g. Frydrychová et al., 2004; Vítková et al., 2005; Lukhtanov \& Kuznetsova, 2010). Telomeres are specialized structures located at the ends of chromosomes that ensure their complete replication and protect them from fusion and abnormal recombinations. In most eukaryotic species, telomeric DNA is marked by the presence of long stretches of conserved short repeats that are synthesized by RNA-depended polymerases (telomerases) (Kipling, 1995). Telomeres of insect species are predominantly composed of a pentanucleotide sequence repeat (TTAGG), which is thought to be an ancestral sequence of telomeres in this class ( $\mathrm{Sa}-$ hara et al., 1999; Frydrychová et al., 2004; Lukhtanov \& Kuznetsova, 2010). However, in some higher-level insect taxa this telomeric motif has been lost during evolution (reviewed in Frydrychová et al., 2004). It seems that this repeat has been lost in entire orders of insects, e.g. true flies, Diptera (Sahara et al., 1999), or within major lineages of an order, e.g. in the true bugs, heteropteran Hemiptera (Kuznetsova et al., 2012) and the parasitic Hymenoptera (Gokhman et al., 2014). Even so, it can also be missed at a much finer taxonomic scale, usually in a repeated man- 
ner, as in the huge beetle order Coleoptera (Frydrychová \& Marec, 2002).

There is a tendency to overgeneralize about the telomeric structure in a group from observations of a very few species and further work may reveal a far greater variety of patterns than previously thought (see e.g. Mravinac et al., 2011). Despite the suborder of the Hemiptera, the Auchenorrhyncha, comprises more than 42,000 valid species (Deitz, 2008), investigations of telomeric DNA sequences have to date been done on only 15 species belonging to 4 genera and 4 families in this group. Frydrychová et al. (2004) were the first to perform Southern hybridization with the "classical" insect telomeric repeat (TTAGG) in Calligypona pellucida F. (Delphacidae). Maryańska-Nadachowska et al. (2013) applied FISH for the first time using the TTAGG repeats to eight species of the spittlebug genus Philaenus (Aphrophoridae), whilst recently Golub et al. (2014) reported FISH telomeric sequences for Mapuchea chilensis (Myerslopiidae). Lastly, as here presented, we provide data on five leafhopper species of the genus Alebra (Cicadellidae). All the species studied to date share TTAGG-type telomere repeats. Since the species investigated are from two phylogeneticallydistant superfamilies, the Fulgoroidea (Delphacidae) and Membracoidea (Aphrophoridae, Myerslopiidae and Cicadellidae), we tentatively conclude that these large superfamilies and perhaps even the hemipteran suborder Auchenorrhyncha as a whole have retained the "classical" insect telomeric motif, (TTAGG). Ultimately though, further empirical work is required to validate this hypothesis.

ACKNOWLEDGEMENTS. We thank the Russian Science Foundation for funding (as grant no. N 14-14-0054) our work at the Zoological Institute of the Russian Academy of Sciences. The collecting trips to Greece and Portugal (D. Aguin-Pombo, 2008-2012) were supported by the FCT research project "Origin of multiple parthenoforms of Empoasca leafhoppers in Madeira Island" (PTDC/BIA-BEC/103411/2008). We are grateful to C. Gantzias for his help in fieldwork. We also sincerely thank two anonymous reviewers, the scientific editor F. Marec and English language editor H.D. Loxdale for their helpful comments which have greatly improved the manuscript.

\section{REFERENCES}

Aguin-Pombo D. 2002: Genetic differentiation among host-associated Alebra leafhoppers (Hemiptera: Cicadellidae). - Heredity 88 : $415-422$.

Aguin-Pombo D., Kuznetsova V.G. \& Freitas N. 2006: Multiple parthenoforms of Empoasca leafhoppers from Madeira Island: where are these unisexual forms coming from? - J. Heredity 97: 171-176.

Aguin-Pombo D., Franquinho Aguiar A.M. \& Kuznetsova V.G. 2007: Bionomics and taxonomy of leafhopper Sophonia orientalis (Homoptera: Cicadellidae), a Pacific pest species in the Macaronesian Archipelagos. - Ann. Entomol. Soc. Am. 100: 19-26.

de Bigliardo G.R., Virla E.G., Caro S. \& Dasso S.M. 2011: Karyotype and male pre-reductional meiosis of the sharpshooter Tapajosa rubromarginata (Hemiptera: Cicadellidae). — Revta Biol. Trop. 59: 309-314.
DeITZ L.L. 2008: Dr Metcalf: A Resource on Cicadas, Leafhoppers, Planthoppers, Spittlebugs, and Treehoppers. (http:// www.lib.ncsu.edu/specialcollections/digital/metcalf/introduction.html (accessed 14 April 2012).

de Lello E., Menezes M. \& Coelho M.I.P. 1982: Chromosomes studies on leafhoppers (Homoptera: Cicadellidae). - Revta Bras. Genét. / Braz. J. Genet. 5: 69-93.

Dietrich C.H. \& Rakitov R.A. 2002: Some remarkable new deltocephaline leafhoppers (Hemiptera: Cicadellidae: Deltocephalinae) from the Amazonian rainforest canopy. $-J$. N. Y. Entomol. Soc. 110: 1-48.

Donlon T.A. \& MAgEnis R.E. 1983: Methyl green is a substitute for distamycin A in the formation of distamycin A/DAPI Cbands. - Hum. Genet. 65: 144-146.

Drosopoulos S. \& LoukAS M. 1988: Genetic differentiation between coexisting color-types of the Alebra albostriella group (Homoptera: Cicadellidae). - Hereditas 79: 434-438.

Drosopoulos S., Loukas M. \& Dimitriou C. 1987: Damage caused by a complex of species or types of the genus Alebra in chestnut trees (Homoptera, Cicadellidae). - Ann. Inst. Phytopathol. Benaki 15: 129-140.

Dworakowska I. 1968: Some Typhlocybinae (Homoptera, Cicadellidae) from Korea, with descriptions of six new species from Korea and one from Vietnam. - Bull. Acad. Pol. Sci. Cl. II (Sci. Biol.) 16: 565-572.

DworaKowsKa I. 1971: On Eastern hemisphere Alebrini (Auchenorrhyncha, Cicadellidae, Typhlocybinae). - Bull. Acad. Pol. Sci. (Sci. Biol.) 19: 493-500.

Emeljanov A.F. \& Kirillova V.I. 1990: Trends and types of karyotype evolution in Cicadina (Homoptera). I. Karyotypic peculiarities and evolutionary changes in the karyotypes of cicadas of superfamily Cicadelloidea. - Entomol. Rev. 69: 62-80.

Fenton B., Birch A.N.E., Malloch G., Woodford J.A.T. \& GonZALEZ C. 1994: Molecular analysis of ribosomal DNA from the aphid Amphorophora idaei and an associated fungal organism. —Insect Mol. Biol. 3: 183-189.

FRYDRYCHOVÁ R. \& MAREC F. 2002: Repeated losses of TTAGG telomere repeats in evolution of beetles (Coleoptera). - Genetica 115: 179-187.

Frydrychová R., Grossmann P., Trubač P., VítKová M. \& Marec F. 2004: Phylogenetic distribution of TTAGG telomeric repeats in insects. - Genome 47: 163-178.

Gillham M.C. 1991: Polymorphism, taxonomy and host plant associations in Alebra leafhoppers (Homoptera: Cicadellidae: Typhlocybinae). - J. Nat. Hist. 25: 233-255.

Gokhman V., Anokhin B. \& Kuznetsova V.G. 2014: Distribution of 18S rDNA sites and absence of the canonical TTAGG insect telomeric repeat in parasitoid Hymenoptera. - Genetica 142: 317-322.

Golub N.V., Kuznetsova V.G. \& Rakitov R.A. 2014: First karyotype data on the family Myerslopiidae (Hemiptera, Auchenorrhyncha, Cicadomorpha). - Comp. Cytogen. 8: 293-300.

Grozeva S. \& Nokkala S. 1996: Chromosome and their meiotic behaviour in two families of the primitive infraorder Dipsocomorpha (Heteroptera). - Hereditas 125: 31-36.

Grozeva S., Kuznetsova V. \& Anokhin B. 2011: Karyotypes, male meiosis and comparative FISH mapping of $18 \mathrm{~S}$ ribosomal DNA and telomeric (TTAGG) ${ }_{n}$ repeat in eight species of true bugs (Hemiptera, Heteroptera). - Comp. Cytogen. 5: 355-374.

Grozeva S., Anokhin B. \& Kuznetsova V.G. 2014: Bed bugs (Hemiptera). In Sharachov I. (ed.): Protocols for Cytogenetic Mapping of Arthropod Genomes. CRC press, Taylor \& Francis, Boca Raton, pp. 285-326. 
HalkKa O. 1959: Chromosome studies on the Hemiptera, Homoptera, Auchenorrhyncha. - Ann. Acad. Sci. Fenn. (A. IV. Biol.) 43: $1-71$.

HamiLton K.G.A. 1995: Evaluation of leafhoppers and their relatives (Insecta: Homoptera: Auchenorrhyncha as indicators of prairie preserve quality. In Hartnett D.C. (ed.): Proceedings of the Fourteenth North American Prairie Conference: Prairie Biodiversity. Kansas State University, Manhattan, pp. 211-226.

Heckmann S., Schroeder-Reiter E., Kumke K., Ma L., Nagaki K., Murata M., Wanner G. \& Houben A. 2011: Holocentric chromosomes of Luzula elegans are characterized by a longitudinal centromere groove, chromosome bending, and a terminal nucleolus organizer region. - Cytogen. Genome Res. 134: 220-228

Howell W.M. \& Black D.A. 1980: Controlled silver staining of nucleolus organizer regions with protective colloidal developer: a 1-step method. - Experientia 36: 1014-1015.

JuAn H. 2011: Studies on the Chromosomes of Chinese Typhlocybinae (Hemiptera: Cicadellidae). MD Thesis. Northwest A\& F University, Yangling, Shaanxi Province, P.R. China, 42 pp. [in Chinese].

KIPLING D. 1995: The Telomere. Oxford University Press, New York, 208 pp.

KiRILlova V.I. 1988: Chromosome numbers of world Homoptera Auchenorrhyncha. II. Cicadelloidea. - Entomol. Rev. 67: 80-107.

Kuznetsova V.G. \& Aguin-Pombo D. (in press): Comparative cytogenetics of Auchenorrhyncha: a review. In Badmin J. \& Webb M. (eds): Leafhoppers of the World and their Relatives. London.

Kuznetsova V.G., Maryańska-NadachowsKa A. \& NoKkala S 2009: Karyotype characterization of planthopper species Hysteropterum albaceticum Dlabola, 1983 and Agalmatium bilobum (Fieber, 1877) (Homoptera: Auchenorrhyncha: Issidae) using AgNOR-, C- and DAPI/CMA3-banding techniques. Comp. Cytogen. 3: 111-123.

Kuznetsova V.G., Grozeva S.M. \& Anokhin B.A. 2012: The first finding of (TTAGG) ${ }_{n}$ telomeric repeat in chromosomes of true bugs (Heteroptera: Belostomatidae: Lethocerus patruelis). Comp. Cytogen. 6: 341-346.

Kuznetsova V.G., Golub N.V. \& Aguin-Pombo D. 2013: Karyotypes, B-chromosomes and meiotic abnormalities in 13 populations of Alebra albostriella and A. wahlbergi (Hemiptera, Auchenorrhyncha, Cicadellidae) from Greece. - Comp. Cytogen. 7: 305-325.

KuZnetsova V.G., MaryańsKa-NadachowsKa A. \& Karamysheva T.V. 2014: Spittlebugs (Hemiptera). Chapter 10. In Sharakhov I. (ed.): Protocols for Cytogenetic Mapping of Arthropod Genomes. CRC press, Taylor \& Francis, Boca Raton, pp. 351-380.

LAUTERER P. 1986: New and interesting records of leafhoppers from Czechoslovakia (Homoptera, Auchenorrhyncha) III. Acta Mus. Morav. 71: 179-187.

LuKhTANOv V.A. \& KuZnetsova V.G. 2010: What genes and chromosomes say about the origin and evolution of insects and other arthropods. - Russ. J. Genet. 46: 1115-1121.

Manicardi G.C., Mandrioli M., Bizzaro D. \& Bianchi U. 2002: Cytogenetic and molecular analysis of heterochromatic areas in the holocentric chromosomes of different aphid species. In Sobti R.C., Obe G. \& Athwal R.S. (eds): Some Aspects of Chromosome Structure and Functions. Narosa, New Delhi, pp. $47-56$.
MaryańsKa-NadachowsKa A., KuZnetsova V.G. \& KaramySHEVA T.V. 2013: Chromosomal location of rDNA clusters and TTAGG telomeric repeats in eight species of the spittlebug genus Philaenus (Hemiptera: Auchenorrhyncha: Aphrophoridae). - Eur. J. Entomol. 110: 411-418.

McKamey S.H. 2002: Leafhoppers of the world database: progress report. In Hoch H., Asche M., Homberg C. \& Kessling P. (eds): Proceedings of the 11th International Auchenorrhyncha Congress, 5-9 August 2002, Potsdam/Berlin, Germany. p. 85.

Monti V., Giusti M., Bizzaro D., Manicardi G.C. \& Mandrioli M. 2011: Presence of a functional (TTAGG) telomere-telomerase system in aphids. - Chromosome Res. 19: 625-633.

Mravinac B., Meštrović N., Čavrak V.V. \& Plohl M. 2011: TCAGG, an alternative telomeric sequence in insects. - Chromosoma 120: 367-376.

Nguyen P., Sahara K., Yoshido A. \& Marec F. 2010: Evolutionary dynamics of rDNA clusters on chromosomes of moths and butterflies (Lepidoptera). — Genetica 138: 343-354.

ROA F. \& GUERRA M. 2012: Distribution of 45S rDNA sites in chromosomes of plants: Structural and evolutionary implications. - BMC Evol. Biol. 12: 225. doi:10.1186/1471-2148-12225.

Sahara K., Marec F. \& Traut W. 1999: TTAGG telomeric repeats in chromosomes of some insects and other arthropods. - Chromosome Res. 7: 449-460.

Schwarzacher T. \& Heslop-Harrison P. 2000: Practical in Situ Hybridization. BIOS, Oxford, 338 pp.

SchweIzER D. 1976: Reverse fluorescent chromosome banding with chromomycin and DAPI. - Chromosoma 58: 307-324.

Southern P.S. \& Dietrich C.H. 2010: Eight new species of Empoasca (Hemiptera: Cicadillidae: Typhlocybinae: Empoascini) from Peru and Bolivia. - Zootaxa 2524: 1-23.

SUMNER A.T. 1972: A simple technique for demonstrating centromeric heterochromatin. - Exp. Cell Res. 75: 304-306.

Viggiani G. 1971: Ricerche sulla entomofauna del Nocciuolo. III. Le Cicadine (Homoptera: Typhlocybidae) I. Identificazione delle specie e reperti biologici preliminari. - Boll. Lab. Entomol. Agr. Filippo Silvestri 29: 149-173.

VítKová M., Král J., Traut W., ZrZavÝ J. \& Marec F. 2005: The evolutionary origin of insect telomeric repeats, (TTAGG) $n^{\text {. }}$ Chromosome Res. 13: 145-156.

WAGNER W. 1940: Zwei neue Zikaden-Arten aus der Umgeburg von Hamburg. - Verh. Ver. Naturw. Heimatforsch. Hamb. 28: $110-113$.

WEI C. 2010: Studies on the Chromosomes of Chinese Deltocephalinae (Hemiptera: Cicadellidae). MD Thesis, Northwest A \& F University, Yangling, Shaanxi Province, P.R. China, 40 pp. [in Chinese].

White M.J.D. 1973: Animal Cytology an Evolution. 3rd ed. Cambridge University Press, London, 468 pp.

Yoshido A., Marec F. \& Sahara K. 2005: Resolution of sex chromosome constitution by genomic in situ hybridization and fluorescence in situ hybridization with (TTAGG) ${ }_{n}$ telomeric probe in some species of Lepidoptera. - Chromosoma 114: 193-202.

Received April 2, 2014; revised and accepted November 26, 2014 Prepublished online February 16, 2015 